STUDENT ARTICLE

\title{
Surgically Assisted Rapid Palatal Expansion as a Treatment for Maxillary Expansion in Adults
}

\section{Hira Abbasi, Abhishek Lal}

Department of Operative Dentistry, Altamash Institute of Dental Medicine Karachi, Pakistan.

Correspondence to: Abhishek Lal, Email: abhishekdarshan@yahoo.com, ORCiD: 0000-0002-0018-7069

\begin{abstract}
Transverse Maxillary Deficiency is a common dental malocclusion that usually presents as constricted maxilla with both functional as well as esthetic effects on the individual suffering from it. Functional appliance can be used in children whose mid palatal suture has not ossified but adults required surgical approach such as surgically assisted rapid palatal expansion. We conducted a literature review of techniques of surgical rapid maxillary expansion, appliances commonly used for expansion and finally the complications associated with it postoperatively. Review of available literature was conducted using literature present in PubMed, Google scholar, ESCO and semantic scholar using the following keywords in combination such as "Surgically assisted rapid palatal expansion", "Hyrax appliance", "Haas Appliance" and "Transverse Maxillary Deficiency". Out of the 210 articles screened, 40 were included in this literature review. Presently, surgically assisted rapid maxillary expansion is a treatment option for patients in their adulthood in which the mid-palatal suture has been closed. Expansion appliances such as Haas and Hyrax are used adjunctively with surgical modalities.
\end{abstract}

Keywords: Adults, Orthodontics, Palatal Expansion, Surgery.

This is an Open Access article distributed under the terms of the Creative Commons Attribution Non-Commercial License (http:// creative commons. org/licenses/by-nc/4.0) which permits unrestricted non-commercial use, distribution, and reproduction in any medium, provided the original work is properly cited.

\section{INTRODUCTION}

Malocclusion is one of the most frequent findings in dentistry ranging from minor disturbance such as involving a single tooth or a group of teeth to severe disturbance such as prognathic or retrognathic upper or lower or both jaws in a patient. Minor problems associated with few teeth such as rotations, crowding, tilted teeth, missing teeth, and supernumerary teeth are relatively easy to correct, especially if the patient is in the growing age group. However, those with severe maxillomandibular disturbances such as prognathism, retrognathism, and transverse jaws discrepancies require more complex treatment options., These complexities such as transverse discrepancy, prognathism and retrognathism in the anteroposterior planes specifically are comparatively easy to manage in growing patients with the use of orthopedic rapid palatal appliances, as compared to fully grown patients such as adults due to difficulties posed by lack of further growth. In such patients, advanced treatment options become of vital importance for the patient such as surgical methods which includes Surgically Assisted Rapid Palatal Expansion (SARPE).
The transverse deficiency of the maxilla is commonly seen in adolescents and adult patients with both syndromic and non-syndromic causes associated with it, with non-syndromic being frequently encountered especially patients with Cleft lip and Palate (CLP). ${ }^{4,5}$ It is Characterized by posterior crossbite, either unilateral, bilateral or a tendency to crossbite. These crossbites may lead to CO-CR shift, causing the patient to shift mandible frequently on closure, leading to temporomandibular pain and dysfunction. Transverse maxillary deficiency has an indirect effect on nasal airflow resistance. it plays no direct role on airway obstruction. Basically, expansion leads to widening of the nasal floor, decreasing airflow resistance.

Moreover, the face form of such patients is also affected which not only has functional impact such as difficulty in chewing and apnea, on the individual on the patient suffering from it, but the psychological effect as well. ${ }^{6}$ This deems it of vital importance to correct such dental disturbance as soon as it has been recognized in a patient.

Now, the patients in growing age group have their maxilla and mandible in a developmental stage where the jaws are undergoing maturational 
changes and intervention at this stage would not only be less invasive but offer more favorable results. At this point, alteration in growth pattern in offer much more favorable and less invasive treatment options as compared to surgical methods.' But for skeletally mature patients with the transverse maxillary discrepancy, surgical and orthodontic both options have to be used simultaneously for its correction. If the skeletal orthopedic expansion of the maxilla is not possible, then three alternative treatment options are available: Rapid Maxillary Expansion (RME), Slow Maxillary Expansion (SME), and SARPE. SME and RME are indicated in patients who are in their growing age whereas SARPE is indicated for individuals who have passed their growth spurt and in whom the mid palatal suture has undergone complete maturation, interdigitation and fusion and has ossified. ${ }^{9}$ Recently, SARPE gained much popularity to treat patients with transverse maxillary hypoplasia in adults. It allows the surgeon to effectively achieve transverse expansion of the maxilla in a skeletally mature patient. ${ }^{3,10}$

For SARPE, three types of expansions have been described: purely tooth borne, purely bone borne, and tooth-bone borne appliances. Now, each type of appliance that is used for the correction of TMD has its drawbacks and benefits. Usually, the transverse maxillary growth significantly slows down and the maxillary suture closes around the age of 14-15 years in males and 15-16 years old in females."Now once the midpalatal suture has been closed, the orthopedic methods for palatal expansion are largely unsuccessful because the growth now has been completed and only dental movements can take place with no effect no skeletal movements. ${ }^{12}$ In adult patients with TMD, SARPE has shown to be successful as compared to orthopedic methods used alone and avoid many complications associated with it. SARPE consists basically of opening the closed suture that resists expansion forces of the maxilla. ${ }^{13}$ The clinical technique for SARPE involves splitting the palatine suture and this widens the maxilla for its expansion. ${ }^{14}$ Although its benefits in adults are immense, some drawbacks associated with it include a costly procedure that requires outpatient surgery and loss of work time as well. Furthermore, more complications that are associated with SARPE includes infections, hemorrhage, pain, unilateral or asymmetric expansion of the maxilla, relapse and periodontal problems. ${ }^{15}$

Review of available literature was conducted using literature present in PubMed, Google scholar, EBSCO and semantic scholar using the following keywords in combination such as "Surgically assisted rapid palatal expansion", "Hyrax appliance", "Haas Appliance" and "Transverse Maxillary Deficiency". Out of the 210 articles screened, 40 were included in this literature review.

The aim of our article is to present a comprehensive literature review that includes indications, diagnosis, case selection for SARPE, a brief overview of the different techniques used for SARPE, and finally the associated risks and complications with SARPE. The rationale of this literature review is to elaborate on SARPE as being a favorable treatment option for patients beyond their growth spurt with TMD.

\section{Indications for Surgically Assisted Rapid Palatal Expansion}

SARPE is the only effective treatment option when skeletal growth of the patient has been completed such as young adults with patients having a constricted maxilla. ${ }^{16}$ Case selection and diagnosis properly is of paramount importance so that the procedure is offered to only those patients who can maximally benefit from it. For those who might benefit from less invasive procedures, SARPE should not be undertaken.

Indications for SARPE include: to increase the parameters of the maxilla when no additional movements in possible non-surgically, provide space for correction of crowded maxillary dentition when no extractions are planned, patients suffering from CLP with maxillary hypoplasia, reduction of unesthetic and excessive buccal corridors in adult patients. ${ }^{17,18}$

\section{Contraindications for Surgically Assisted Rapid Palatal Expansion}

At times, SARPE is not useful for the patients and may in turn be harmful to the patients. So, it is of vital importance to properly diagnosis a patient with the suspect of having Transverse Maxillary Deficiency.

Although there are no absolute contraindications for performing SARPE in patients with TMD, there are some instances where this treatment might not be useful for the patients such as patients suffering from untreated coagulopathies where there is an increased risk of persistent bleeding when undergoing the treatment. So, methods of controlling a patient's underlying coagulopathies must be addressed before being medically fit for the surgery. 19,20

\section{Etiology associated with Transverse Maxillary Deficiency}

Patients who usually suffer from Transverse Maxillary Deficiency have many factors that might predispose them to develop such a condition. Commonly TMD is frequently associated with: Habits such as thumb 
sucking, iatrogenic (CLP repair), and patients suffering from obstructive sleep apnea. Although less frequently, TMD is also associated with some syndromes such as Cleft lip and Palate, Marfan syndrome, and Klippel-Feil syndrome. Moreover, further less frequently, encountered causes are craniosynostosis and nonsyndromic palatal synostosis.'

\section{Diagnosis and Case Selection for SARPE}

The primary indication for SARPE is in patients who are skeletally mature with no further growth of the maxilla. Diagnosis of TMD in such patients can be challenging at times because of minimal tissue changes with it and it easily overlooked by focusing on other skeletal and dental discrepancies. The main clinical diagnostic findings in such patients are unilateral or bilateral crossbite, narrow nasal base, narrow tapering maxillary arch form, narrow and deep palatal vault and hypoplastic zygomatic bones. Due to the treatment option of SARPE being only effective on certain patients, proper case selection is of prime importance. Favorable results of SARPE in noted in patients who are in adolescence or adulthood in which skeletal growth of the maxilla has been completed, patients suffering from skeletal class 3 malocclusion and isolated constricted maxilla leading to further problems such as crossbites and sleep apnea. ${ }^{22}$

\section{Surgical Technique of SARPE}

After diagnosis and case selection, the patient is then ready for the procedure. Firstly, the patient is anesthetized with either an endotracheal tube or nasoendotracheal tube. Then, local anesthesia is administered in the peripheries of the maxilla to block the infra-orbital nerve, nasopalatine nerves, and greater palatine nerves. The initial incision is made in the buccal vestibule starting from the $1^{\text {st }}$ molar up to the canine region. Now, the buccal osteotomy is performed in the anterior maxillary region using a reciprocating saw. ${ }^{23}$ Next, the palatine incision is made over the midpalatal suture starting from the posterior aspect of the incisive canal up to the posterior edge of the hard palate, with the use of an elevator to reflect palatal mucosa for propervisualization. Using the reciprocating saw, a palatal osteotomy is started at the posterior edge of the hard palate, with a $2 \mathrm{~mm}$ cut lateral to the mid-palatal suture all the way to the posterior limit of the incisive canal. On the contralateral side, similar incisions and cuts are made with both the cuts of either side joined together. This is called as paramedian palatal osteotomy. The next step is the midline osteotomy, starting with a vertical incision in the midline in the alveolar mucosa between the two maxillary central incisors and then the periosteal elevator is used for soft tissue reflection. Now the fine straight osteotome is engaged into the interdental bone between the maxillary central incisors and using the non-dominant index finger, the palatal cortical bone is broken through. With the osteotomies performed, an

Table 1: Description of SARPE article to evaluate its results

\begin{tabular}{|c|c|c|c|c|c|}
\hline Type of Study & $\begin{array}{c}\text { Reference } \\
\text { No. }\end{array}$ & $\begin{array}{l}\text { Targeted } \\
\text { Sample }\end{array}$ & & Method & Results \\
\hline Case Report & 22 & 1 & SARPE & Real-time PCR & $\begin{array}{l}\text { Successful procedure } \\
\text { without complications }\end{array}$ \\
\hline Case Report & 30 & 1 & SARPE & $\begin{array}{c}\text { Reverse } \\
\text { transcriptase } \\
\text { quantitative PCR } \\
\text { (RT-qPCR) }\end{array}$ & $\begin{array}{l}\text { Increase in nasolabial } \\
\text { angle, increase in upper } \\
\text { lip length, and increase } \\
\text { in upper incisor } \\
\text { exposure }\end{array}$ \\
\hline Case Report & 31 & 1 & SARPE & Real-time PCR & $\begin{array}{l}\text { Midpalatal synostosis } \\
\text { complication occured }\end{array}$ \\
\hline $\begin{array}{l}\text { Prospective } \\
\text { Study }\end{array}$ & 32 & 31 & SARPE & $\begin{array}{l}\text { nCoV real-time } \\
\text { polymerase chain } \\
\text { reaction }\end{array}$ & $\begin{array}{l}\text { SARPE normalizes the } \\
\text { transverse discrepancies } \\
\text { and is stable for mean of } \\
6 \text { years post treatment }\end{array}$ \\
\hline $\begin{array}{l}\text { Randomized } \\
\text { Trial }\end{array}$ & 33 & 30 & SARPE & Multiplex RT-PCR & $\begin{array}{c}\text { Palatal areas and } \\
\text { volumes were stable } \\
\text { with no retention other } \\
\text { than expander required }\end{array}$ \\
\hline
\end{tabular}

J Dow Univ Health Sci 2021, Vol. 15 (3): 169-174 
expansion device is now placed to expand the previously constricted maxilla of the patient..$^{4}$ Finally, the wound is irrigated properly and thoroughly and all the incisions performed are now closed.8 Some studies also report conducting alternative techniques to perform SARPE that includes modifications in the traditional technique. ${ }^{25,26}$

Tooth Borne Rapid Maxillary Expansion Appliances Expansion devices are the final step of the SARPE which finally initiates the expansion of the constricted maxilla. The most frequently used tooth-borne appliance is the Hyrax appliance. A Hyrax appliance is a tooth-borne appliance used as bands which are placed on the teeth, frequently on premolars and molars with expansion screw in between. ${ }^{27}$ Now, the skeletal effect of this appliance is clearly appreciated as the expansion of the mid-palatal suture of the patients with an increase in the nasal floor and palate floor as well. Moving on towards the dentoalveolar changes associated with hyrax appliance, buccal tipping movement is from frequently found in such patients with pronounced alveolar bending. Although the expansion of the palate does occur when the Hyrax appliance is used, tooth-bone borne appliance offers a more reliable expansion of the palate. $^{28,29}$

\section{Tooth-Bone Rapid Maxillary Expansion Appliances} Haas appliance is a type of tooth-bone expansion device that offers rapid maxillary expansion to produce separation of the mid-palatal suture. ${ }^{34}$ The appliance consists of a jackscrew which is designed for palatal expansion. The primary indication of the use of this appliance is in late mixed or early primary dentition before the mid-palatal suture is completely ossified or as an adjunctive measure to SARPE. ${ }^{35}$ Although both Hyrax and Haas appliance is designed to offer an expansion of palate, the mode of function is different for both of them. However, studies to report no significant difference between them when concerning about the palatal expansion offered by each of them. ${ }^{36}$ Furthermore, both Haas and Hyrax appliance is known to have dentoalveolar effects such as tipping movement, but this is a more pronounced finding in patients using Hyrax appliance.'

\section{Comparison of Haas and Hyrax Appliances}

After surgically the mid-palatal suture has been opened, the next step is to use expansion appliances that will expand the previously constricted maxilla. Now both Hyrax and Haas appliances are commonly used to expand the maxilla and offer similar expansion. ${ }^{38,39}$ The primary difference between both of the appliances is 172 that acrylic support for Haas appliances comes from the palate. The choice of expander then depends on the shape of the palate of the patient. Haas appliance is considered as the first choice when the transverse width and depth of the palate is sufficient enough.

Furthermore, these two expanders has also indirect effect of expansion on nasal cavity been used to expand the nasal cavity in patients with obstructive Sleep Apnea to improve apnea with studies reporting Hyrax appliance to be more effective in expanding the nasal cavity as compared to Haas appliance. ${ }^{40}$

\section{Complications associated with SARPE}

This treatment modality is quite useful for the patients such as those in adulthood and late teenage years, as successful results are now being obtained from it. ${ }^{41}$ Still, many patients are hesitant in getting their treatment done at an earlier age which can easily avoid the need for surgical procedures on the patients which are more traumatizing. Some of the complications frequently encountered in such patients after SARPE procedures include asymmetrical expansion, postoperative bleeding, infection, increased pain sensations, gingival recession, tooth loss, tooth discoloration, and peri-operative bleeding. ${ }^{42-44}$

Furthermore, some short-term complications may arise in these patients such as nerve injury, hemorrhage, and appliance related problems. ${ }^{45}$ However some studies do conclude the occurrence of such complications after SARPE to be rare with the evaluation of risk factors as an important adjunctive to avoid such complications. ${ }^{46}$

\section{CONCLUSION}

Treatment options are available for both growing and non-growing patients although patients in growing stages benefit better from a wide range of options available for them which are relatively less invasive as compared to non-growing patient's procedures.

Surgically Assisted Rapid Palatal Expansion is a growing and beneficial treatment option for non-growing patients with adjunctive use of expansion appliances such as Haas and Hyrax expanders after the surgical procedure.

AUTHORS' CONTRIBUTION: HA: Drafted the manuscript and literature review and final analysis of the manuscript.AL: Drafted the manuscript and literature review.

CONFLICTS OF INTEREST: None to declare.

FUNDING: None declared by the author.

Received: March 03, 2021

Accepted: June 14, 2021 


\section{REFERENCES}

1. Zere E, Chaudhari PK, Sharan J, Dhingra K, Tiwari N. Developing Class III malocclusions: challenges and solutions. Clin Cosmet Investig Dent 2018;10:99-116. doi: $10.2147 /$ CCIDE.S134303

2. Converse JM, Coccaro PJ. Diagnosis and treatment of maxillomandibular dysplasias. Am J Orthod 1975; 68:625-44. doi: 10.1016/0002-9416(75)90097-4

3. Rachmiel A, Turgeman S, Shilo D, Emodi O, Aizenbud D. Surgically Assisted Rapid Palatal Expansion to Correct Maxillary Transverse Deficiency. Ann Maxillofac Surg 2020; 10:136-41. doi: 10.4103/ams.ams 163 19

4. Abd Rahman N, Abdullah N, Samsudin AR, Naing Mohd Ayub Sadiq L. Dental anomalies and facial profile abnormality of the non-syndromic cleft lip and palate children in kelantan. Malays J Med Sci 2004; 11:41-51.

5. Bouletreau P, Raberin M. Incorporating the maxillary transverse dimension in the treatment plan. J Dentofacial Anomalies Orthod 2016; 19:304.

6. Isik BK, Alparslan ES, Menziletoglu D. Surgery-Assisted Fast Maxillary Expansion: A Review. J Atatürk Univ Faculty Dent 2016; 141-6.

doi.org/10.17567/ataunidfd.290612

7. Ahmed VS. Indian Board of Orthodontics Case ReportDr. Prem Prakash Memorial Award. J Indian Orthod Soc 2017; 51:192-9.

8. Suri L, Taneja P. Surgically assisted rapid palatal expansion: a literature review. Am J Orthod Dentofacial Orthop 2008; 133:290-302.

doi: 10.1016/j.ajodo.2007.01.021

9. Abo Samra D, Hadad R. Midpalatal suture: evaluation of the morphological maturation stages via bone density. Prog Orthod 2018; 19:29.

doi: $10.1186 / \mathrm{s} 40510-018-0232-2$

10. da Costa Senior O, Smeets M, Willaert R, Shaheen E, Jacobs R, Politis C. Complications Following OneStage Versus Two-Stage Surgical Treatment of Transverse Maxillary Hypoplasia. J Oral Maxillofac Surg 2021; :S0278-2391(21)00201-9.

doi: 10.1016/j.joms.2021.02.025

11. Korn EL, Baumrind S. Transverse development of the human jaws between the ages of 8.5 and 15.5 years, studied longitudinally with use of implants. J Dent Res 1990; 69:1298-306.

doi: $10.1177 / 00220345900690061501$

12. Jimenez-Valdivia LM, Malpartida-Carrillo V, RodriguezCardenas YA, Dias-Da Silveira HL, Arriola-Guillen LE. Midpalatal suture maturation stage assessment in adolescents and young adults using cone-beam computed tomography. Prog Orthod 2019; 20:38. doi: 10.1186/s40510-019-0291-z

13. Betts NJ, Vanarsdall RL, Barber HD, Higgins-Barber K, Fonseca RJ. Diagnosis and treatment of transverse maxillary deficiency. Int J Adult Orthodon Orthognath Surg 1995; 10:75-96.
14. Romero H, Irias N, Guifarro J, Estrada A, Umanzor V, Caballero F, et al. Surgically assisted rapid expansion in two patients with maxillary transverse deficiency. MOJ Orthop Rheumatol 2020; 12:45-8.

doi: $10.15406 /$ mojor.2020.12.00516

15. Kim YK. Complications associated with orthognathic surgery. J Korean Assoc Oral Maxillofac Surg 2017; 43:3-15. doi: 10.5125/jkaoms.2017.43.1.3

16. Brunetto DP, Sant'Anna EF, Machado AW, Moon W. Non-surgical treatment of transverse deficiency in adults using Microimplant-assisted Rapid Palatal Expansion (MARPE). Dental Press J Orthod 2017; 22:110-25.

doi: 10.1590/2177-6709.22.1.110-125.sar

17. Maheshwari RK, Harani H, Joshi S, Tiwari A. Surgically assisted rapid palatal expansion: A way to treat transverse maxillary deficiency. Int J Orthodontic Rehab 2018; 9:107.

18. Aktop S, Gonul O, Garip H, Goker K. Surgically Assisted Maxillary Expansion. In: A Textbook of Advanced Oral and Maxillofacial Surgery Volume 2 [Internet]. InTech; 2015. Available from: http://www.intechopen.com/ books/a-textbook-of-advanced-oral-andmaxillofacial-surgery-volume-2/surgically-assistedmaxillary-expansion.

19. Grybauskas S, Moser L, Esteves L, Cintra O, SchneiderMoser U. An interview with Simonas Grybauskas. Dental Press J Orthod 2018; 23:14-35. doi: 10.1590/2177-6709.23.4.014-035.int

20. Spahn DR, Bouillon B, Cerny V, Duranteau J, Filipescu D, Hunt BJ, et al.The European guideline on management of major bleeding and coagulopathy following trauma: fifth edition. Crit Care 2019; 23:98.

doi: 10.1186/s13054-019-2347-3

21. Goos JAC, Mathijssen IMJ. Genetic Causes of Craniosynostosis: An Update. Mol Syndromol 2019; 10:6-23. doi: $10.1159 / 000492266$

22. Behnia H, Mohammad-Rahimi H, Behnaz M. Treatment of an Adult Skeletal Class III Patient with Surgically Assisted Rapid Palatal Expansion and Facemask. Case Rep Dent 2019; 2019:8251903.

doi: $10.1155 / 2019 / 8251903$

23. Hernandez-Alfaro F, Mareque Bueno J, Diaz A, Pages CM. Minimally invasive surgically assisted rapid palatal expansion with limited approach under sedation: a report of 283 consecutive cases. J Oral Maxillofac Surg 2010; 68:2154-8.

doi: 10.1016/j.joms.2009.09.080

24. Madhavarajan S, Taylor N, Johnson P. Surgically assisted Rapid Palatal Expansion (SARPE). Br J Oral Maxillofac Surg [Internet]. 2014 Oct;52(8):e59-60. Available from: https://linkinghub.elsevier.com/ retrieve/pii/So266435614003192

25. Gonzalez Lagunas J. Hueto Madrid JA, Raspall Martin G: Vertical incisions in SARPE. Rev Esp Cir Maxillofac 2005; 27:151.

26. Park KN, Lee CY, Park IY, Kim JY, Yang B. Surgically 
assisted rapid palatal expansion with tent screws and a custom-made palatal expander: a case report. Maxillofac Plast Reconstr Surg 2015; 37:11.

doi: 10.1186/s40902-015-0011-7

27. Agarwal A, Mathur R. Maxillary Expansion. Int J Clin Pediatr Dent 2010; 3:139-46.

doi: 10.5005/ip-journals-10005-1069

28. Lin L, Ahn HW, Kim SJ, Moon SC, Kim SH, Nelson G. Tooth-borne vs bone-borne rapid maxillary expanders in late adolescence. Angle Orthod 2015; 85:253-62. doi: $10.2319 / 030514-156.1$

29. Krusi M, Eliades T, Papageorgiou SN. Are there benefits from using bone-borne maxillary expansion instead of tooth-borne maxillary expansion? A systematic review with meta-analysis. Prog Orthod 2019; 20:9. doi: 10.1186/s40510-019-0261-5

30. Sierra OV, Meraz WS, Cárdenas JM, Cantú FJ, Murga HM. Assessment of facial changes after a surgicallyassisted rapid palatal expansion: case report. Revista Mexicana de Ortodoncia 2017; 5:85-8.

31. Lanigan DT, Mintz SM. Complications of surgically assisted rapid palatal expansion: review of the literature and report of a case. J Oral Maxillofac Surg 2002; 60:104-10. doi: 10.1053/joms.2002.29087

32. Magnusson A, Bjerklin K, Nilsson P, Marcusson A. Surgically assisted rapid maxillary expansion: longterm stability. Eur J Orthod 2009; 31:142-9.

doi: $10.1093 /$ ejo/cjno74

33. Prado GP, Pereira MD, Biló JP, Furtado F, Ferreira LM. Stability of surgically assisted rapid palatal expansion: a randomized trial. J Dent Res 2013; 92:49S-54S. doi: $10.1177 / 0022034513486899$

34. Gunyuz Toklu M, Germec-Cakan D, Tozlu M. Periodontal, dentoalveolar, and skeletal effects of tooth-borne and tooth-bone-borne expansion appliances. Am J Orthod Dentofacial Orthop 2015; 148:97-109.

doi: 10.1016/j.ajodo.2015.02.022

35. Algharbi M, Bazargani F, Dimberg L. Do different maxillary expansion appliances influence the outcomes of the treatment? Eur J Orthod 2018; 40:97106. doi: $10.1093 /$ ejo/cjx035

36. Facanha AJ, Lara TS, Garib DG, da Silva Filho OG. Transverse effect of Haas and Hyrax appliances on the upper dental arch in patients with unilateral complete cleft lip and palate: a comparative study. Dental Press J Orthod 2014; 19:39-45. doi: 10.1590/2176-9451.19.2.039-045.oar
37. Kilic N, Kiki A, Oktay H. A comparison of dentoalveolar inclination treated by two palatal expanders. Eur J Orthod 2008; 30:67-72. doi: $10.1093 /$ ejo/cjmog9

38. Weissheimer A, de Menezes LM, Mezomo M, Dias DM, de Lima EM, Rizzatto SM. Immediate effects of rapid maxillary expansion with Haas-type and hyrax-type expanders: a randomized clinical trial. Am J Orthod Dentofacial Orthop 2011; 140:366-76.

doi: 10.1016/j.ajodo.2010.07.025

39. Weissheimer A, de Menezes LM, Mezomo M, Dias DM, de Lima EM, Rizzatto SM. Immediate effects of rapid maxillary expansion with Haas-type and hyrax-type expanders: a randomized clinical trial. Am J Orthod Dentofacial Orthop 2011; 140:366-76.

doi: 10.1016/j.ajodo.2010.07.025

40. Amini FA, Ramezanei GH. Comparison of the effect of Haas and Hyrax rapid palatal expanders on nasal cavity dimensions. J Dent Med 2009; 22: 110-5.

41. Koca CG, Guvenc IS. Surgically-assisted Rapid Maxillary Expansion under Local Anesthesia. J Coll Physicians Surg Pak 2019; 29:S129-S131.

doi: 10.29271/icpsp.2019.12.S129

42. Smeets M, Da Costa Senior O, Eman S, Politis C. A retrospective analysis of the complication rate after SARPE in 111 cases, and its relationship to patient age at surgery. J Craniomaxillofac Surg 2020; 48:467-71. doi: 10.1016/j.jcms.2019.12.015

43. Haq J, Lo M, Collier J. Five-year experience of SARPE in a craniofacial setting: outcomes, complications and learning points. Br J Oral Maxillofac Surg 2017; 55:e756. doi.org/10.1016/j.bjoms.2017.08.332

44. Feldmann I, Bazargani F. Pain and discomfort during the first week of rapid maxillary expansion (RME) using two different RME appliances: A randomized controlled trial. Angle Orthod 2017; 87:391-6. doi: 10.2319/091216-686.1

45. Verquin M, Daems L, Politis C. Shortterm complications after surgically assisted rapid palatal expansion: a retrospective cohort study. Int J Oral Maxillofac Surg 2017; 46:303-8. doi: 10.1016/j.ijom.2016.11.016

46. Williams BJ, Currimbhoy S, Silva A, O'Ryan FS. Complications following surgically assisted rapid palatal expansion: a retrospective cohort study. J Oral Maxillofac Surg 2012; 70:2394-402. doi: 10.1016/j.joms.2011.09.050 